http://jmscr.igmpublication.org/home/

ISSN (e)-2347-176x ISSN (p) 2455-0450

crossref DOI: https://dx.doi.org/10.18535/jmscr/v7i8.119

Journal Of Medical Science And Clinical Research

\title{
Sclerotherapy with Polidocanol for Treatment of Aneurysmal Bone Cyst
}

\author{
Authors \\ Gunjan Upadhyay ${ }^{1}$, Ghanapriya Singh ${ }^{2}$, Indrajit Sardar ${ }^{3}$, Madhulika Singh ${ }^{4}$ \\ ${ }^{1}$ Calcutta Medical Research Institute, Diamond Harbour Road, Kolkata \\ Ex Resident -Institute of Post Graduate Medical Education And Research. \\ ${ }^{2}$ Ass.Professor, Nituk (for technical and radiological support), PhD (IIT Delhi) \\ ${ }^{3}$ Senior Orthopaedic Consultant, Nightingale Hospital, Kolkata \\ ${ }^{4}$ Ex Resident, Maulana Azad Medical College, New Delhi
}

\begin{abstract}
Percutaneous Scelrotherapy (1) is a safe alternative to surgery for Aneurysmal Bone Cyst.

We present a follow up case for the same.

Methods: We retrospective analyzed data from our patient with repeated injection of Polidocanol(2).Each injection consisted of 2-4 mg polidocanol per $\mathrm{kg}$ of body weight.

Results: All cysts healed in time.

Interpretation: Our results shows percutaneous sclerotherapy with polidocanol has high efficiency in treatment of $A B C$ with a low frequency of side effect.

Aneurysmal bone cysts $(A B C)(3)$ are rare expansile osteolytic tumour with annual incidence of 0.14 per $10^{5}$.

Sclerosant acts by causing damage to endothelium of vessels and starting a coagulation cascade that results in thrombosis.

Keywords: 1.Sclerotherapy 2.Polidocanol 3.Aneurysmal Bone Cyst.
\end{abstract}

\section{Introduction}

Aneurysmal bone cysts $(\mathrm{ABC})$ is a rare tumour found in adolescent age group, equally in both males and females (Jaffe \& Lichtenstein -1942; Leithnes et al 1999).

$\mathrm{ABC}$ is expansile osteolytic tumour with incidence of $0.14 / 10^{5}$.

Treatment options for $\mathrm{ABC}$ are

\section{EMBOLIZE}

2. CURETTAGE

3. BONE GRAFT \& CEMENTATION

4. SCLEROTHERAPY

Polidocanol is used for varicose vein since 1960.

For ABC, Polidocanol was documently used by Jain et al.
Rastogi et al in 2006, gave case series of 72 patient with $97 \%$ success rate

Varshney et al 2010-Sclerotherapy more effective than surgery.

We present our success with usage of polidocanol as sclerosant in ABC patients in study since 2017 till now.

\section{Patients Selection}

Radiologically and Cytologically confirmed ABC patients with proper consent and after explanation of all risks, complications and requirement of future surgery (may be) were taken for treatment.

Patient and relatives were counselled and approval was taken for publication. 


\section{JMSCR Vol||07||Issue||08||Page 704-707||August}

\section{Materials and Methods}

Since 2017 till 2019, patients were treated and regular follow up was done.

Instruments: $18 \mathrm{G}$ needle

2-4 $\mathrm{mg}$ Polidocanol/kg body weight

\section{Methods}

We used the $18 \mathrm{G}$ needle to draw fluid aspirate, presence of blood in aspirate suggested active disease.

Routinely 3 injection of polidocanol was given at 4 week interval. We needed maximum up to 6 such dosage before we found clinical \& radiological improvement in few cases.

\section{Results}

After a mean follow up of about an year we could match our success with the earlier research done on similar project.

No patient had any recurrence or any major adverse effect.

Clinical conditioned improved and bone quality improved with gradual decrease in the size of cysts.

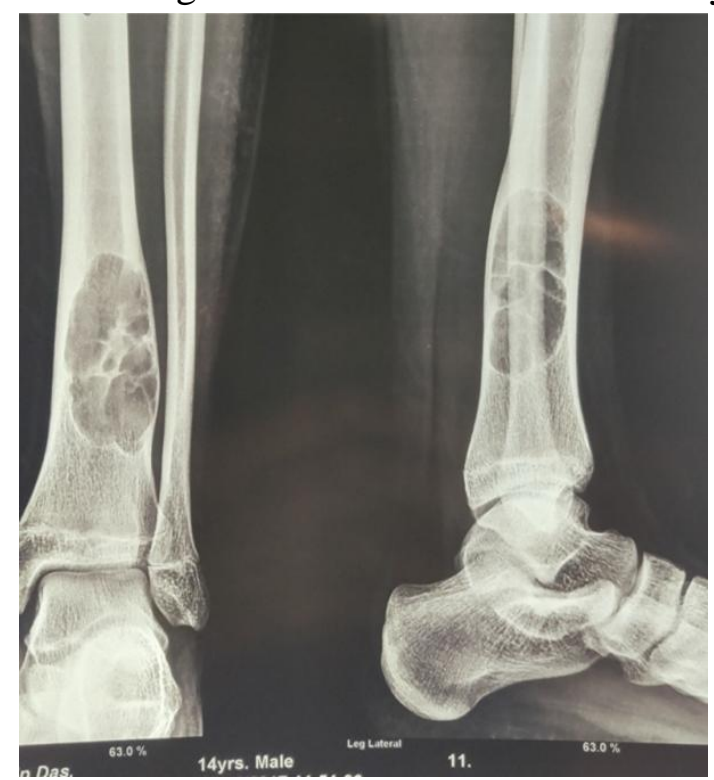

Figure 1: X-ray at first visit to clinic

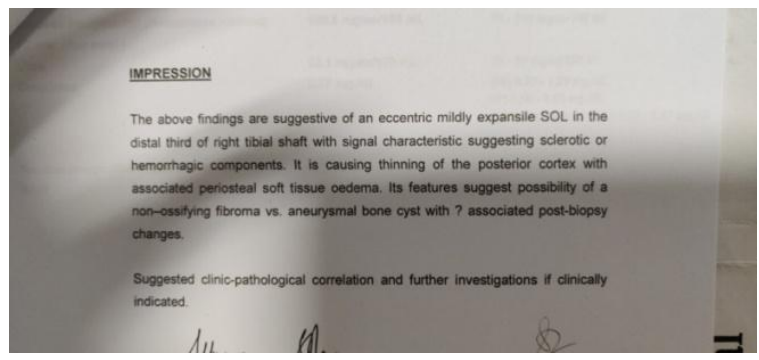

Figure 2: MRI Report

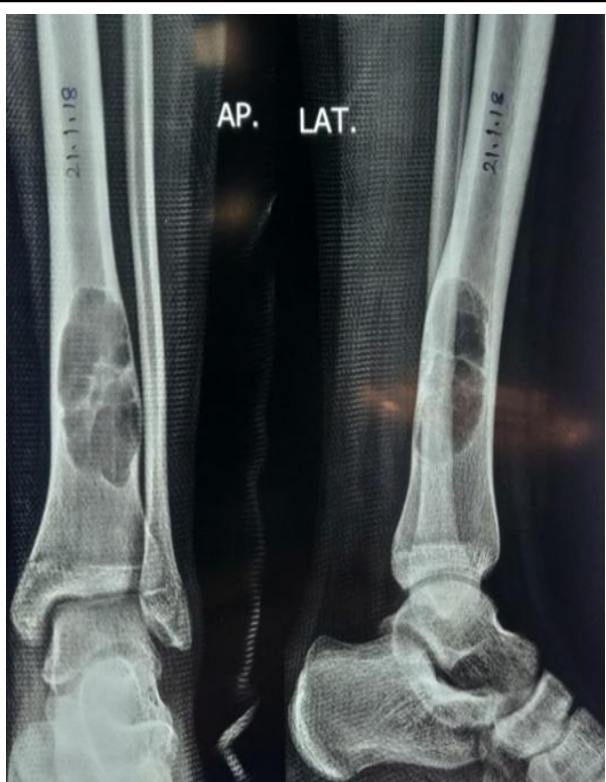

Figure 3: First Injection Dose (21/1/18)

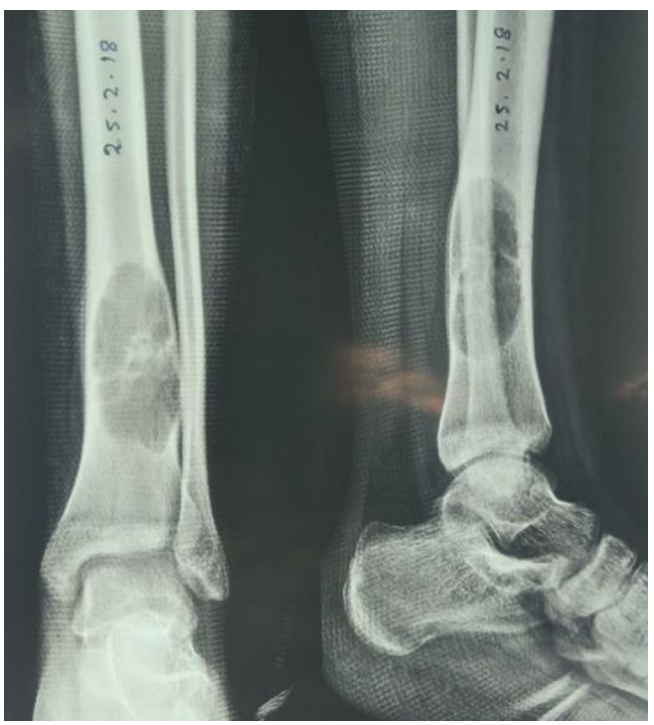

Figure 4: Second Injection Dose (25/2/18)

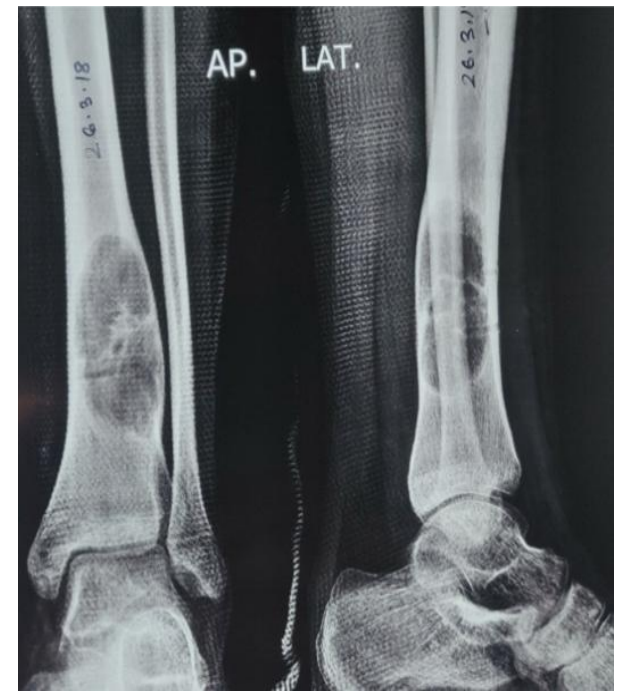

Figure 5: Third Injection Dose (26/03/18) 


\section{JMSCR Vol||07||Issue||08||Page 704-707||August}

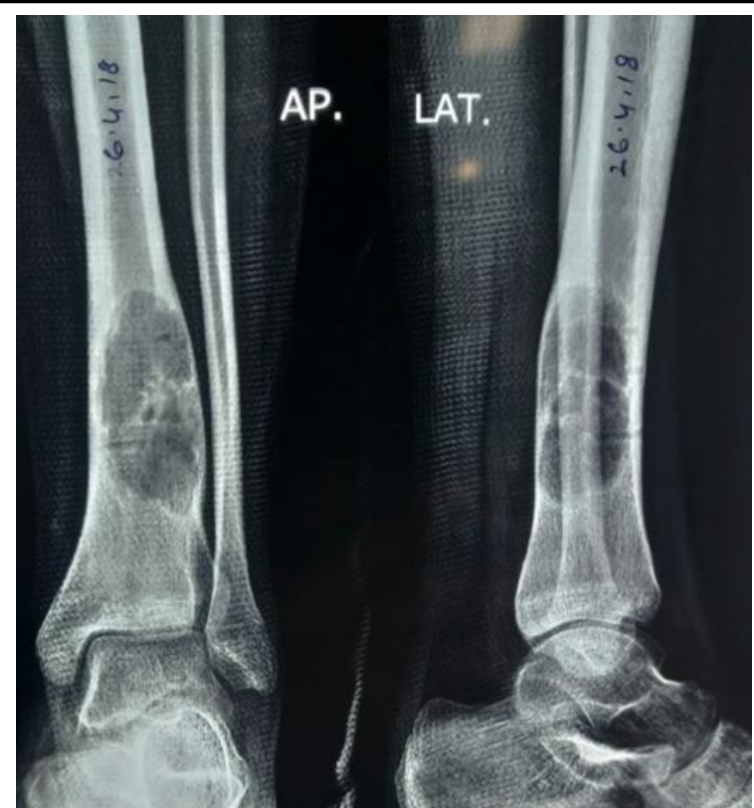

Figure 6: Fourth Injection Dose (26/4/18)

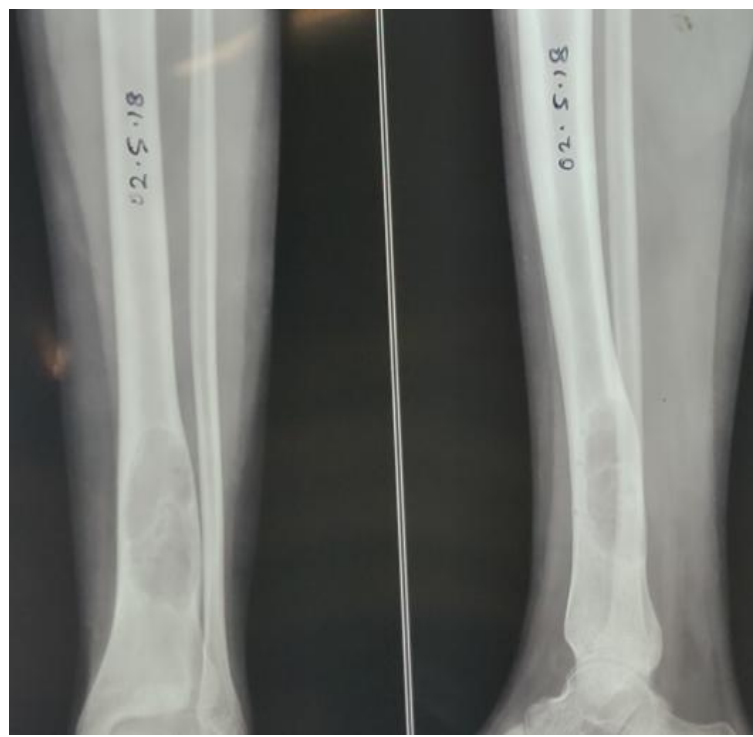

Figure 7: Fifth Injection Dose (02/05/18)

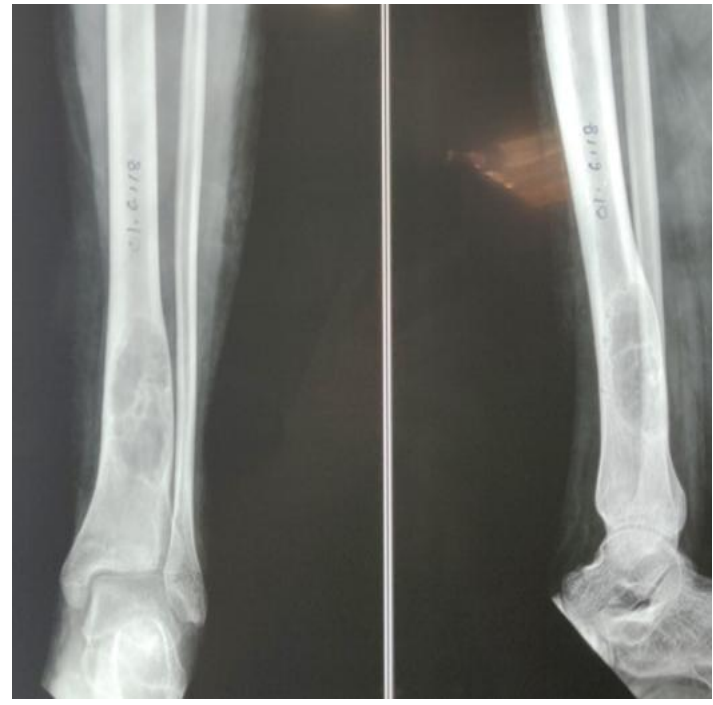

Figure 8: Sixth Injection Dose (01.06.2018)

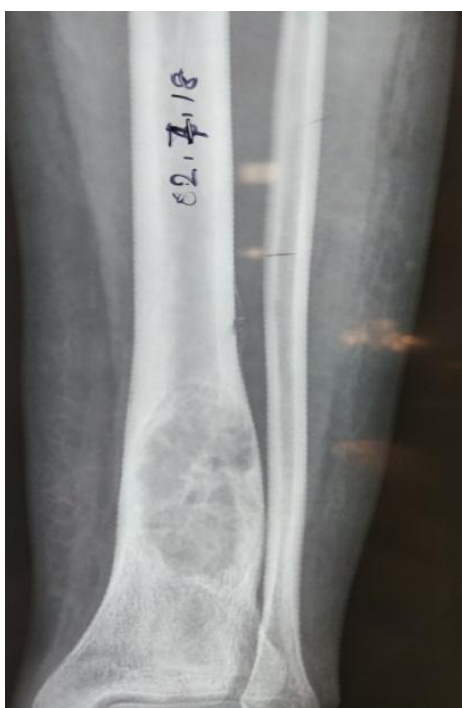

Figure 9: 6 Months after Last Injection

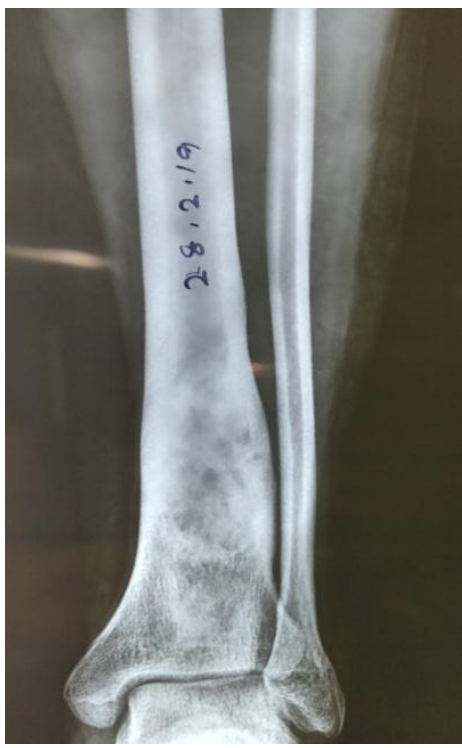

Figure 10: 7 Months After Last Injection

\section{Discussion}

Open curette and bone grafting has $30 \%$ recurrence. Wide en bloc excision $-100 \%$ cures but the morbidity associated was not encouraging.

Radiation therapy has also been tried.

So the best available treatment was with sclerosant i.e. POLIDOCANOL.

However need of multiple injection and prolong treatment appears as a disadvantage of the procedure.

In our study we got excellent success with no recurrence till date \& no complications like anaphylaxis etc. following the procedure.

Hence we promote treatment of polidocanol therapy as sclerosant in $\mathrm{ABC}$. 


\section{Acknowledgement}

We would whole heartedly thank the publishing team, the editor and all concerned for giving us a chance to present our work through there esteemed journal.

We would take this opportunity to thank our entire patient, the staff, nurses and technician who served us to make this project a grand success.

We are thankful to our colleagues Dr Madhulika, Ass Prof Ghanapriya, my teacher PROF. A. K. PAL (HOD Orthopaedics), Dr Indrajit Sardar and all our students, friend and families who provided expertise that greatly assisted the research. I will also mention of my grandparents, my parents and my family who sacrificed their all for my success.

Lastly I will like to thank god with folded hand for all he has bestowed on me.

\section{References}

1. Sclerotherapy: a study comparing polidocanol in foam and liquid form.

2. Ankara Universitesi Tip Fakültesi, Genel Cerrahi Anabilim Dali, Ibni Sina Hastanesi, K-4 Blok, 06100 Ankara, Turkey.

3. Polidocanol for endovenous microfoam sclerosant therapy.

4. University of Pennsylvania, 331 John Morgan Building/6112, 3620 Hamilton Walk, Philadelphia, PA 19104-4215, USA.

5. Efficacy and safety of sclerotherapy using polidocanol foam: a controlled clinical trial.

6. Servicio de Angiología y Cirugía Vascular, Hospital de Mataró, Mataró, Barcelona, Spain.

7. Sonographically guided percutaneous sclerosis using $1 \%$ polidocanol in the treatment of vascular malformations.Jain R, Bandhu S, Sawhney S, Mittal R Clin Ultrasound. 2002 Sep; 30(7):416-23. PubMed

8. Is sclerotherapy better than intralesional excision for treating aneurysmal bone cysts?
Varshney $\quad \mathrm{MK}^{1}$, Rastogi S, Khan SA, Trikha V.

9. Jain et al-use of polidocanol as an endogenous sclerosing agent to treat varicose veins has been recently found useful in treatment of $\mathrm{ABC}$.

10. Rastogi et al -In case series of 72 patients treated with Polidocanol a cure rate of $97 \%$. 